\title{
Optimization of Comminution Circuit Throughput and Product Size Distribution by Simulation and Control Quarterly Technical Progress Report
}

Report Period Start Date:

Report Period End Date:
October 01, 2004

December 31, 2004

\author{
Authors: \\ S. K. Kawatra - Principal Investigator \\ T. C. Eisele, T. Weldum, D. Larsen, R. Mariani, J. Pletka
}

Date of Issue:

January 2005

DOE Award Number:

DE-FC26-01NT41062

\section{Submitting Organization}

Department of Chemical Engineering

Michigan Technological University 1400 Townsend Drive Houghton, MI 49931 - 1295 


\section{DISCLAIMER:}

This report was prepared as an account work sponsored by an agency of the United States Government. Neither the United States Government nor any agency thereof, nor any of their employees, makes any warranty, express or implied, or assumes any legal liability or responsibility for the accuracy, completeness, or usefulness of any information, apparatus, product, or process disclosed, or represents that its use would not infringe privately

owned rights. Reference herein to any specific commercial product, process, or service by trade name, trademark, manufacturer, or otherwise does not necessarily constitute or imply its endorsement, recommendation, or favoring by the United States Government or any agency thereof. The views and opinions of authors expressed herein do not necessarily state or reflect those of the United States Government or any agency thereof. 


\begin{abstract}
The goal of this project is to improve energy efficiency of industrial crushing and grinding operations (comminution). Mathematical models of the comminution process are being used to study methods for optimizing the product size distribution, so that the amount of excessively fine material produced can be minimized. The goal is to save energy by reducing the amount of material that is ground below the target size, while simultaneously reducing the quantity of materials wasted as "slimes" that are too fine to be useful. This is being accomplished by mathematical modeling of the grinding circuits to determine how to correct this problem. The approaches taken included (1) Modeling of the circuit to determine process bottlenecks that restrict flowrates in one area while forcing other parts of the circuit to overgrind the material; (2) Modeling of hydrocyclones to determine the mechanisms responsible for retaining fine, high-density particles in the circuit until they are overground, and improving existing models to accurately account for this behavior; and (3) Evaluation of advanced technologies to improve comminution efficiency and produce sharper product size distributions with less overgrinding.
\end{abstract}




\section{Table of Contents}

Introduction $\quad 5$

Executive Summary $\quad 5$

$\begin{array}{ll}\text { Experimental } & 7\end{array}$

Results and Discussion $\quad 8$

$\begin{array}{ll}\text { Conclusions } & 11\end{array}$

$\begin{array}{ll}\text { References } & 12\end{array}$

\section{List of Tables and Graphical Materials}

Figure 1. Novel comminution circuit developed and simulated in this project.

$\begin{array}{ll}\text { Figure 2: Original, unmodified fine comminution circuit. } & 7\end{array}$

Figure 3: Size distribution of mill feed stream in the unmodified 8 grinding circuit.

Figure 4: Efficiency curves for the single-stage hydrocyclone used to segregate the intermediate-size particles into a separate stream.

Figure 5: Size distributions of mill feeds for the combined closed circuit (CC) / open circuit (OC) circuit shown in Figure 1.

Figure 6: Comparison of products from the 2-stage circuit with products from the single-stage circuit.

Table 1: Comparison of throughputs for the two grinding circuit configurations simulated. 


\section{Introduction}

While crushing and grinding (comminution) of various feedstocks is a critical operation in mining, as well as in a range of other industries, it is both energy-intensive and expensive, with tremendous room for improvement. A neglected route in optimizing the comminution process is the minimizing of overgrinding. Since grinding particles to finer than the target size both wastes energy and produces unusable product, such overgrinding must be minimized in order to improve energy efficiency. The objective of this project is therefore to sample and simulate a full-scale iron ore processing plant to determine methods for increasing grinding circuit energy efficiency by minimizing overgrinding.

Plant sampling and analysis has demonstrated that the largest single source of overgrinding in the industrial process is the return of high-density material to the grinding process by hydrocyclones. The particles of high-density iron oxides that are near the cut size are fully liberated and do not require further comminution, but they are returned to the mill rather than being removed as final product. A fundamental redesign of the comminution circuit is therefore needed to deal with these intermediate-size dense particles.

After creating models for the unit operations in the plant, alternative circuit configurations were devised that could reduce the amount of material being recirculated and overground. Simulations of these circuits indicate that substantial reductions of the circulating load can be achieved, resulting in an increase in throughput of approximately $50 \%$ while using the same number of grinding mills, with a corresponding increase in energy efficiency.

\section{Executive Summary}

The goal of a comminution circuit is to grind particles to their liberation size, so that the valuable minerals are completely broken free from the gangue minerals. For the best grinding efficiency, all particles should ideally be ground only to the liberation size, and no finer. In order to accomplish this, the circuit should have the following characteristics:

1. Material should be removed from the circuit as soon as it is sufficiently fine, otherwise particles retained in the circuit have the opportunity to break further.

2. Breakage at the coarser sizes should be maximized, as a coarse particle breaking does not produce as many extremely fine particles as a finer particle breaking will produce.

3. All particles of the target size should have equal probability of being removed by the classification system, regardless of factors such as particle density. 
An additional characteristic has been identified in this project: it is important that particles that are already near the desired target size be ground just sufficiently to reach the specified size. This means that the near-size particles should be subjected to at most one breakage event, and then removed from the circuit.

To accomplish this, the circuit shown in Figure 1 was devised based on the body of data generated earlier in this project.

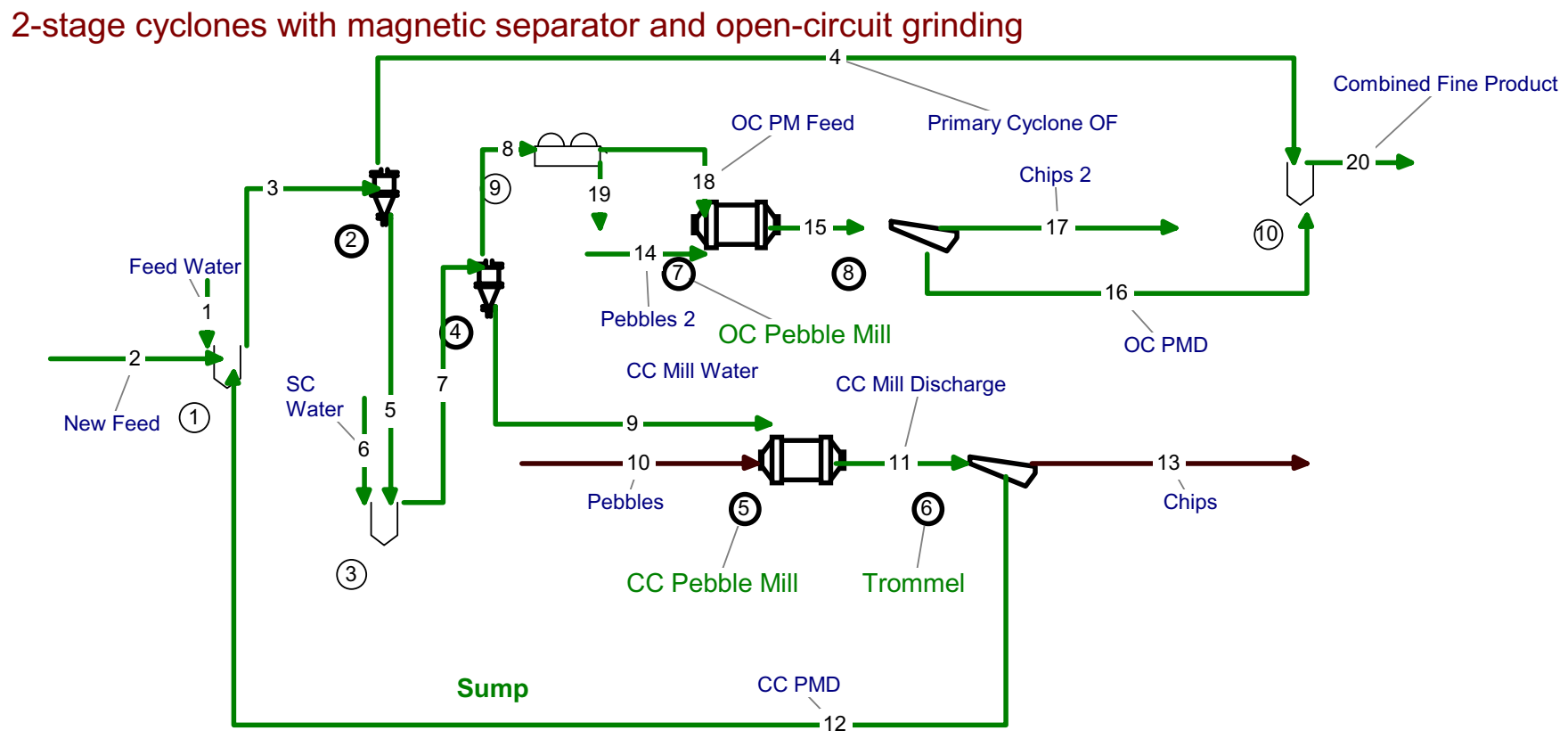

Figure 1. Novel comminution circuit developed and simulated in this project.

The key features of this novel circuit are:

1. It uses a pair of hydrocyclones to separate the particles which are just slightly coarser than the target size into a separate stream, which consists of very nearly monosized particles.

2. This stream of intermediate size particles, instead of recirculating to a closedcircuit mill, is diverted to a mill operating in open circuit. The particles going through the open circuit mill are subjected to only a very limited number of breakage events, and so the probability of a particle being broken more than once, and overground as a result, is minimal. Since the particles are nearly monosized, the product from the open circuit mill remains very narrow.

As a result of the novel features of this flowsheet, the intermediate-sized particles that would normally make up a large fraction of the circulating load (and would therefore both tend to be overground, and would tend to decrease the mill capacity by increasing its circulating load) is prevented from interfering with the grinding of the coarser fraction. 
Simulations of this circuit indicated that this new configuration would have roughly $50 \%$ greater throughput than a conventional circuit using the same number of mills, and that the energy consumption per ton of material ground would be reduced accordingly. This gain is primarily due to a great reduction in the circulating load to the closed-circuit mill.

These results have been presented to plant personnel, who are currently deciding which plant would be most appropriate for a plant-scale test of this circuit configuration.

\section{Experimental}

Simulation models were prepared using data previously collected from a plant operated by one of the industrial partners on this project. The original, unmodified circuit was as shown below in Figure 2. Hydrocyclone and grinding mill model parameters used were described in previous progress reports.

1-stage cyclones with closed circuit mill (base configuration)

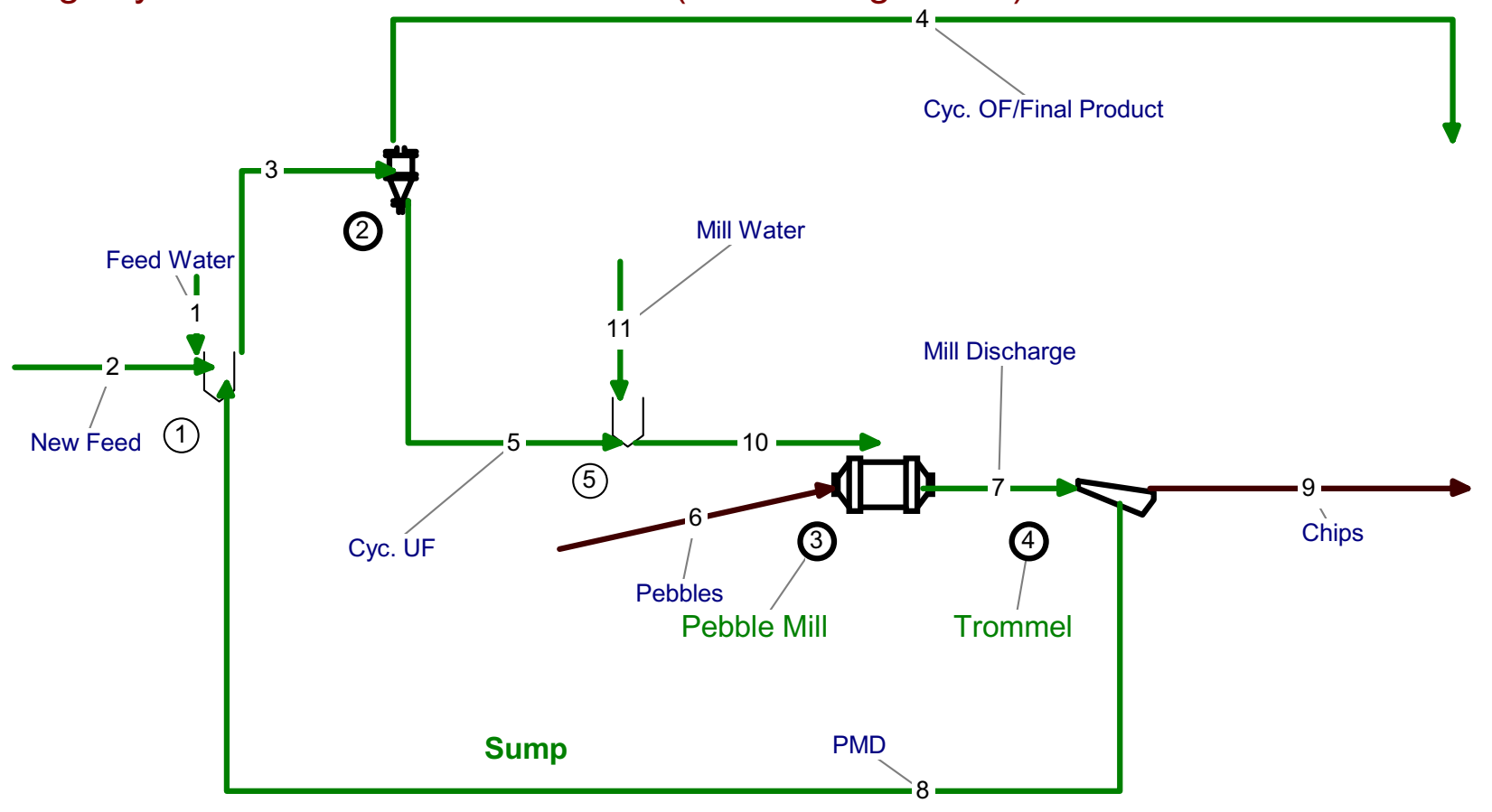

Figure 2: Original, unmodified fine comminution circuit. Plant sampling and analysis demonstrated that this circuit, which operated with approximately $250 \%$ recirculating load in stream \#8, tended to significantly overgrind the high-density magnetite particles.

After modeling this base circuit, the circuit was reconfigured as shown in Figure 1, to reduce the tendency for overgrinding of intermediate-sized particles. The modified circuit, with two grinding mills, was directly compared to a pair of mills operating in parallel circuits of the type shown in Figure 2. 


\section{Results and Discussion}

The base circuit operates with a $250 \%$ circulating load, which results in the mill feed having the size disribution shown here in Figure 3. It should be noted that the overall mill feed is dominated by the size distribution of the magnetic material (which is primarily high density iron oxides), and that this magnetic material is significantly finer than the nonmagnetic fraction. Much of this material has already been ground to finer than the target product size, and should ideally be removed rather than being recirculated to the mill.

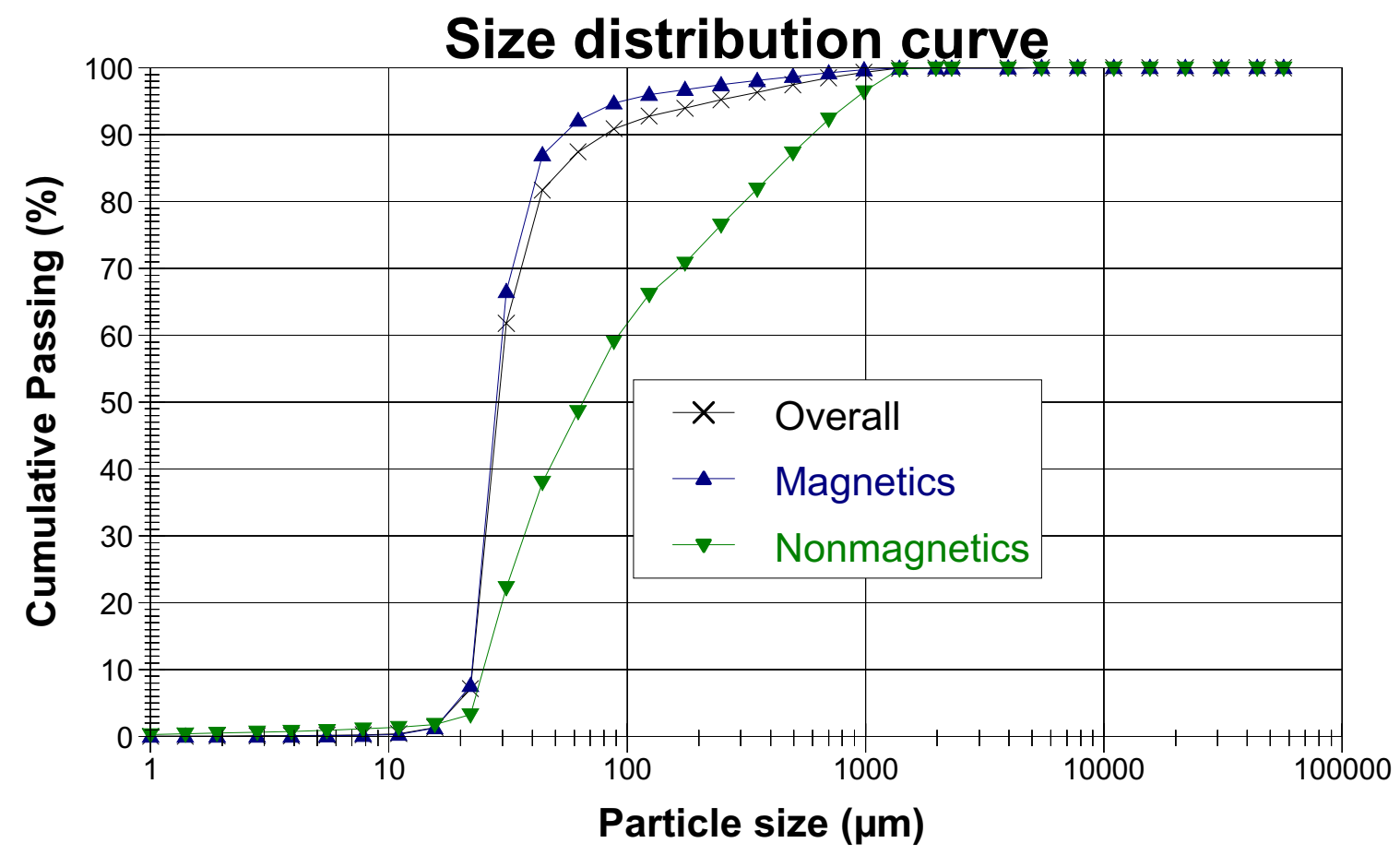

Figure 3: Size distribution of mill feed stream in the unmodified grinding circuit. Note that the magnetic material is significantly finer than the nonmagnetics, indicating that the high-density magnetic materials are being preferentially returned to the mill and overground.

The first task was to determine hydrocyclone parameters that would allow the intermediate-size particles, which were slightly coarser than the desired product size, to be separated as a very narrowly-sized fraction from the bulk of the mill slurry. This was done by using two stages of hydrocyclone separation, with the second cyclone having a slighly coarser separation size than the primary cyclone. This is shown in the hydrocyclone efficiency curves given in Figure 4. 


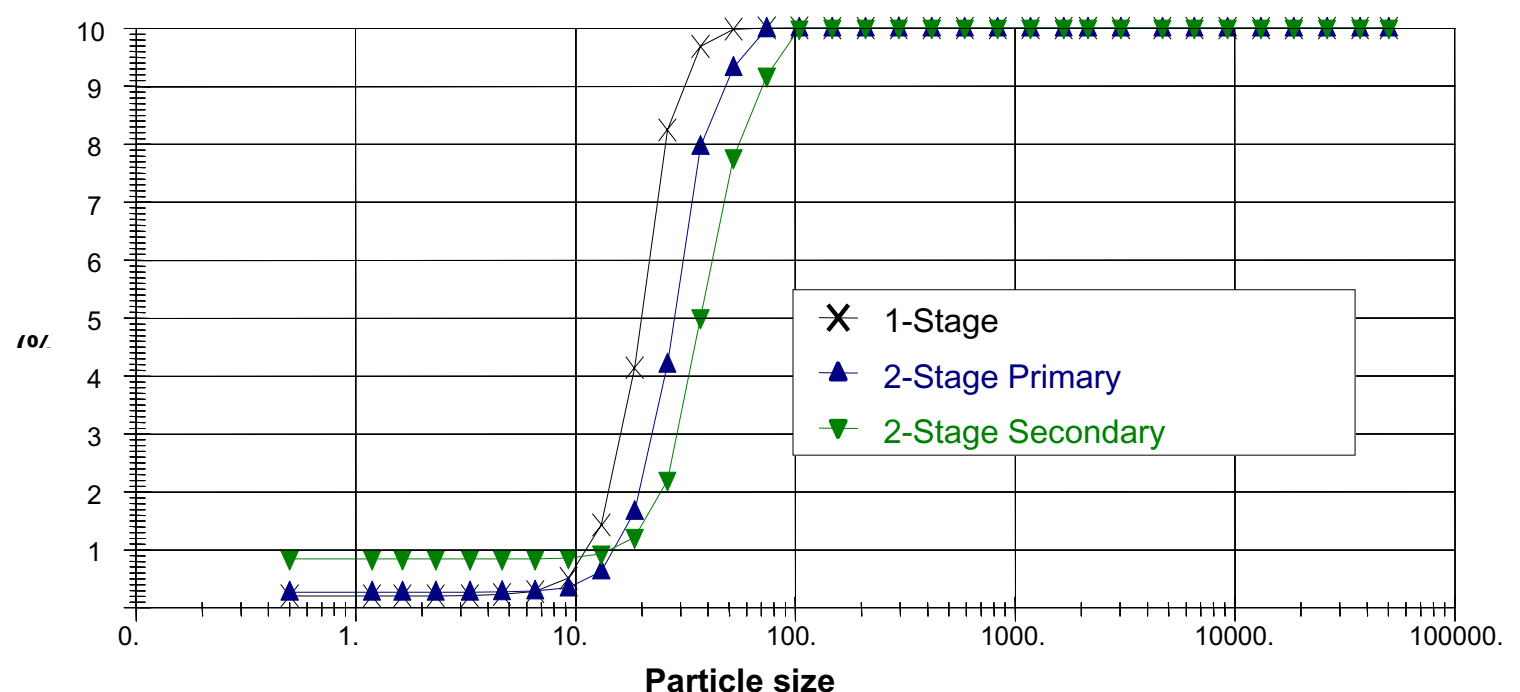

Figure 4: Efficiency curves for the single-stage hydrocyclone used in the unmodified circuit, and for the two-stage cyclones developed to segregate the intermediate-size particles into a separate stream.

Using this pair of hydrocyclones, two distinct grinding mill feeds could be produced, as shown in Figure 5. The key features seen in this graph are, first, that the closed-circuit (CC) mill was receiving a much coarser and broader size distribution than the opencircuit (OC) mill, and the OC mill feed was so sharp as to be nearly monosized.

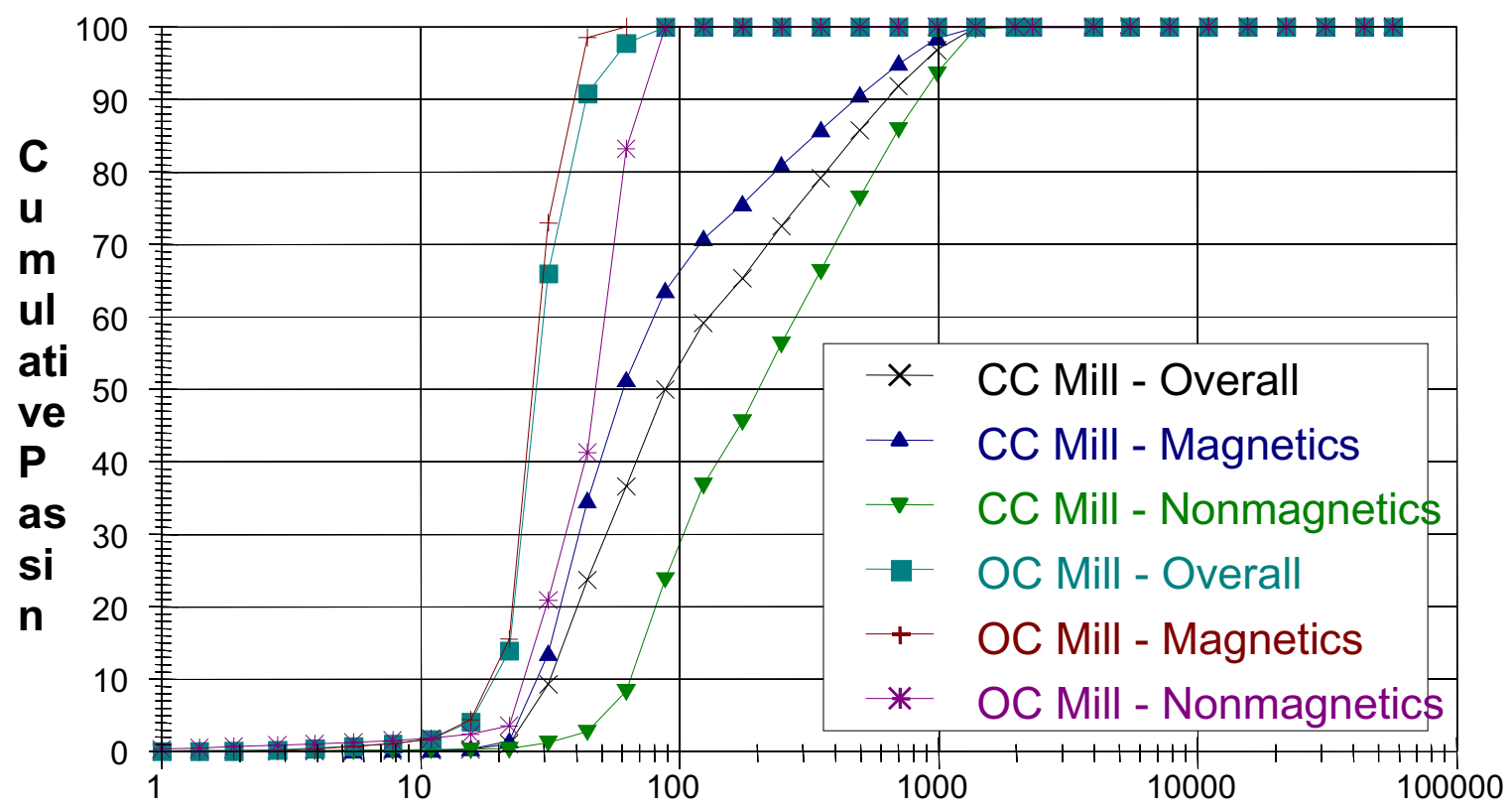

Particle size

Figure 5: Size distributions of mill feeds for the combined closed circuit (CC) / open circuit (OC) circuit shown in Figure 1. 
Second, the separation between the magnetic and non-magnetic size distributions for each of the feeds shown in Figure 5 was much less than was seen for the unmodified mill feed, seen in Figure 3. This indicates that retention and overgrinding of the high-density magnetic fraction was much reduced.

When the 2-stage open/closed grinding circuit products were compared with the product from the unmodified circuit, the results shown in Figure 6 were determined. It is seen that the open-circuit grinding portion of this circuit actually slightly improved the sharpness of the grind, and overall the final product quality for the 2-stage circuit was as good as the quality for the 1-stage circuit.

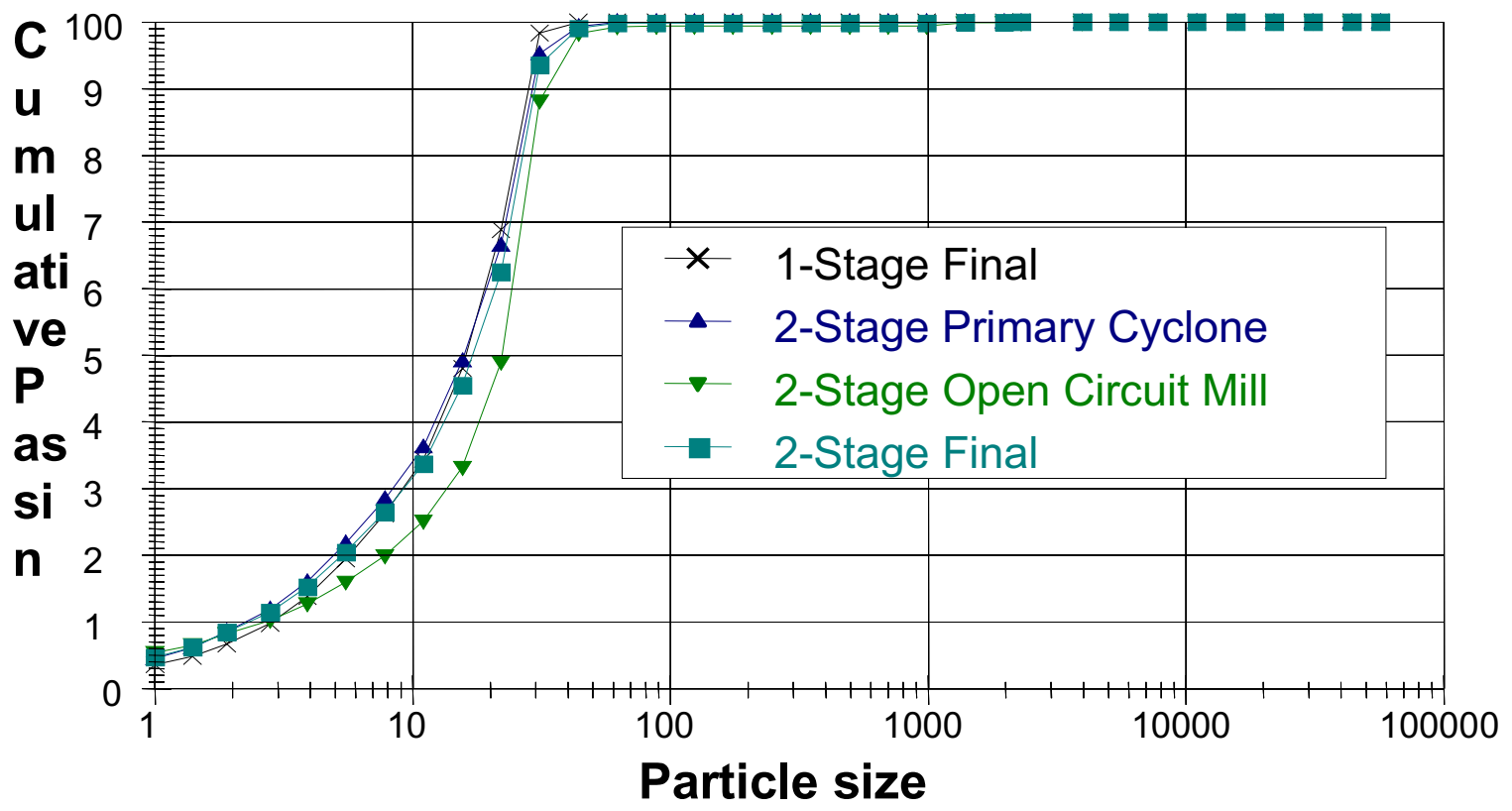

Figure 6: Comparison of products from the 2-stage circuit with products from the single-stage circuit.

The key difference between the two circuit configurations is seen when the throughputs and circulating loads are compared, as shown in Table 1. In this comparison, a pair of unmodified grinding circuits is compared to a single two-stage grinding circuit, since the two-stage circuit uses two mills while the single-stage circuit uses only one. It can be seen that there is a substantial decrease in circulating load in the two-stage circuit, at only $42.5 \%$ as compared with $250 \%$ for the unmodified circuit. As a result of this reduction in circulating load, a considerable amount of grinding capacity was made available for grinding fresh feed, to the extent that the overall circuit capacity was increased by approximately $50 \%$. This represents a major improvement in operation. Since for both circuits the mills are operating with the same quantity of material filling them, they 
require approximately the same quantity of energy to turn regardless of whether they are in the single-stage configuration or the two-stage configuration. However, the large increase in throughput means that the quantity of energy to grind a ton of ore will be decreased comparably, by approximately $50 \%$.

Table 1: Comparison of throughputs for the two grinding circuit configurations simulated.

\begin{tabular}{|l|l|l|}
\hline Process Stream & $\begin{array}{l}\text { Pair of 1-Stage } \\
\text { Circuits }\end{array}$ & 2-Stage Circuit \\
\hline Circuit Feed & $240 \mathrm{t} / \mathrm{h}$ & $360 \mathrm{t} / \mathrm{h}$ \\
\hline Circulating Load & $606 \mathrm{t} / \mathrm{h}(253 \%)$ & $153 \mathrm{t} / \mathrm{h}(42.5 \%)$ \\
\hline $\begin{array}{l}\text { Primary Cyclone } \\
\text { Feed }\end{array}$ & $846 \mathrm{t} / \mathrm{h}$ & $513 \mathrm{t} / \mathrm{h}$ \\
\hline $\begin{array}{l}\text { OC Mill Feed } \\
\text { Primary Cyclone } \\
\text { Overflow }\end{array}$ & $240 \mathrm{t} / \mathrm{h}$ & $81 \mathrm{t} / \mathrm{h}$ \\
\hline
\end{tabular}

These results indicate a significant breakthrough in preventing the overgrinding problem and the accompanying waste of energy. The plant personnel are keenly interested in implementing this new configuration, as even a fraction of this efficiency increase would be worth millions of dollars in operating cost reductions.

\section{Conclusions}

Simulations of novel grinding circuit configurations have indicated an extremely promising potential arrangement for boosting grinding efficiency by as much as $50 \%$ in iron ore grinding circuits, by greatly reducing the overgrinding of high-density iron oxide minerals. Development of this circuit required the use of comminution models based on actual plant data, as without such models it would not have been possible to prove the benefits of this configuration without excessive plant modification costs. 


\section{References}

L.G. Austin, R.R. Klimpel, P.T. Luckie. 1984. Process Engineering of Size Reduction: Ball Milling. Society of Mining Engineering, AIME. New York

A.R. Laplante and J.A. Finch, 1984. The Origin of Unusual Cyclone Performance Curves. International Journal of Mineral Processing, Volume 13, p 1 - p 11.

T.J. Napier-Munn, S. Morrel, R.D. Morrison, T. Kojovis. 2001. Mineral Comminution Circuits, Their Operation and Optimization. JKMRC Monograph Series in Mining and Mineral Processing 2. Australia.

L. R. Plitt, 1976, “A Mathematical Model of the Hydrocyclone Classifier”, CIM Bulletin, December, pp. 114-123

W. J.Whiten, 2004, Personal Communication, March 15

SSI, 2003. Systat Version 10.2, Systat Software Inc., <http://www.systat.com> 